\title{
A Political Economy Model of Capital Expropriation and Skilled Migration
}

\author{
Kirk A. Collins \\ Schwartz School of Business, St. Francis Xavier University, Antigonish, Canada \\ Email: kcollins@stfx.ca
}

Received July 4, 2013; revised August 4, 2013; accepted August 13, 2013

Copyright (C) 2013 Kirk A. Collins. This is an open access article distributed under the Creative Commons Attribution License, which permits unrestricted use, distribution, and reproduction in any medium, provided the original work is properly cited.

\begin{abstract}
This paper studies the interplay of capital resources in a small open economy by way of a general equilibrium political economy model. Normative implications for human capital migration resulting from physical capital lobbying are analyzed. Findings reveal that lobbying designed to mitigate the capital levy problem leads to increased human capital migration and that optimal tax policy for a social welfare maximizing government necessarily implies "brain drain". The implication being that skilled migration may be an inevitable by-product of a self-interested government. As such, while governments may vow to do something to stem the flow of their "best and brightest", the financial pull of increased revenues appears simply too great to imply anything other than lip service, when general equilibrium effects are considered. As a corollary, we find that restrictions on political contributions are welfare enhancing in the two-sided expropriations model we present.
\end{abstract}

Keywords: Lobbying; Migration; Human Capital; Taxation; General Equilibrium

\section{Introduction}

Much has been made about highly skilled or human capital migration, the so-called brain drain, in political circles. ${ }^{1}$ Governments remain concerned that there will be (or will continue to be) shortages in key areas of the economy, such as health care, education and science (see, e.g., Gibson and McKenzie [2]). Researchers have shown that skilled migration is a persistent and somewhat dominant pattern in our globalized economy, but need not present negative externalities in all situations (Docquier and Rapoport [3]). The analysis here contributes, in part, to the externality arguments presented in previous research by adding an overlooked and under-analyzed synergistic behavior between capital resources in an open economy; namely, the interplay between physical and human capital that results from political economy decisions. We illustrate this relationship between the capital resources by way of a general equilibrium political economy model that permits lobbying by owners of physical capital and migration by workers, the owners of human capital, if you will. ${ }^{2}$ It is in this latter sense that we also add to the literature on capital expropriation and it is where the main value-added of the paper originates.

${ }^{1}$ For a discussion on the importance of human capital, in general, see, e.g., Davies and Whalley [1].
The traditional capital levy problem relates to the underinvestment in physical capital that arises because of government incentives to expropriate surplus from sunk capital, since it imposes little deadweight loss (Eichengreen [6]). Researchers have explored various iterations of the problem, such as reversibility of physical capital investments in the presence of lobbying (Marceau and Smart [7]), persistence of inefficient policies in equilibrium as a result of sunk costs (Coate and Morris [8]), and lobbying by owners of sunk capital (Garfinkel and Lee [9]). Building on this and using the work of Bernheim and Whinston [10] as a starting point, our model takes into account the influence of human capital in the expropriations argument; thereby, it affects the two-sided argument we advocate and the one that has yet to be fully explored in the literature. ${ }^{3}$

By modeling this interdependence amongst capital re-

\footnotetext{
${ }^{2}$ Heckman and Klenow [4] and Heckman, Lochner and Taber [5] have examined human capital policy and general equilibrium cost-benefit effects of policy initiatives, but do not model the critical political economy ideas we are expressing here. That is, rather than simply examine the effects per se, we are examining the government's perception of and/or role in these effects.

${ }^{3}$ While not expressed here, given the focus of the paper, the model also adds to the growing literature of computational models in political economy; those with no closed-form solution. For a discussion of such models and their value, see e.g., Kollman, Miller and Page [11].
} 
sources, we find that if the link is strong enough between human and physical capital and/or individuals are sufficiently mobile, then taxing one type of capital in favor of another may lead to (more) harmful disincentive effects and may even reduce the overall tax revenue of the government; the possibility that a change in the tax rate on physical or human capital may lead to spillover effects, which can have positive or negative repercussions on the residual capital, can also not be ruled out. ${ }^{4}$ We show that in its effort to maximize the welfare of its constituents, a government will face inevitable human capital loss as a result. Optimal policy dictates that the government maximize welfare of non-migrants at the expense of this select cohort of highly skilled workers; as such, the loss of individuals at the upper end of the human capital ladder is simply an unfortunate byproduct of a self-interested government. ${ }^{5}$ Therefore, while governments may vow to do something to stem the flow of their "best and brightest”, the financial pull of increased revenues appears simply too great to imply anything other than lip service, when general equilibrium effects are considered. The reason for the outcome is that a marginal increase in labor taxation, culminating in some skilled migration, is less detrimental than a marginal drop in public goods, which would manifest if no tax increase were enacted. Given this, we find that it is indeed advantageous to have a restriction on capital lobbying for countries that bleed top talent (i.e. experience negative political economy externalities) and it can go a long way in mitigating the implications that this two-sided capital levy problem has on skilled migration.

The rest of the paper is organized as follows: Section 2 introduces the model, while Section 3 presents the implications of lobbying and human capital migration; Section 4 provides some concluding remarks.

\section{Model}

\subsection{Preferences and Payoffs}

Consider a small open economy in which one public good-labeled good 0 -and $N$ private consumption goods-labeled $1,2, \cdots, N$-are produced. We shall assume that the public good is non-traded, while the $N$ private goods are freely traded. The world price of good $i$,

\footnotetext{
${ }^{4}$ Pecorino [12] examines the interesting question of the effect of tax structure on long run growth of income and consumption. To do so, he relies on changing the tax mix between human and physical capital, which must satisfy an exogenously determined government budget constraint. Similar in its treatment to Marceau and Smart [7], the question being addressed is not a political economy one, and as such differs from the work undertaken here.

${ }^{5}$ This finding goes against that of Razin, Sadka and Swagel [13] that suggests migration does not necessarily tilt the political balance in favor of those with the power to create this hold-up problem. In other words, the fiscal leakage they talk about does not seem to be present, when general equilibrium considerations are taken into account; at least not to the same extent they talk about.
}

$i=1, \cdots, N$ is denoted by $\bar{p}_{i}$. The industry that produces good $i$ is called industry $i$. Each private good is produced by a single industry, using labor and capital. As for the public good, it is produced by the government, also with inputs of labor and capital.

There exists a continuum of consumers in this economy and, to simplify, we shall normalize the population size to 1 . The population is divided into two major groups: capitalists and workers. Workers earn their living by supplying part of their time endowment - normalized to 1 - on the labor market. Capitalists do not work. They are the owners of capital stocks in the private sector, which constitute the sources of their income. Let $\gamma_{i}>0$, $i=1, \cdots, N$ denote the fraction of the population who are the owners of the capital stock in industry $i$. We suppose that the group that consists of the owners of the capital stock in industry $i$ and the group that consists of the owners of the capital stock in industry $j, j \neq i$, are disjoint. As a group, the capitalists thus make up a fraction of the population equal to $\left(\gamma_{1}+\gamma_{2}+\cdots+\gamma_{N}\right)$ while the proportion of the population who are workers is given by $\left(1-\gamma_{1}-\gamma_{2}-\cdots-\gamma_{N}\right)$. We shall assume that for each $i$ the owners of the capital stock in industry $i$ are equal residual claimants of the profits made by the industry. Workers, however, are assumed to differ in their earning capacity - specifically, by their human capital level. The human capital level of a worker is denoted by $\theta$. To avoid corner solutions the distribution of types among workers is represented by a continuous density function $h: \theta \rightarrow h(\theta)$, with $h(\theta)>0$ for all $\theta \geq 0$ where

$$
\int_{0}^{\infty} h(\theta) \mathrm{d} \theta=1-\sum_{i=1}^{N} \gamma_{i} .
$$

To model the difference in earnings due to variation in human capital levels, we shall assume that labor inputs are measured in effective labor units and that for each hour that a worker of type $\theta$ spends in the production of a good, she provides $\theta$ units of effective labor input. If we let $\omega$ denote the wage rate paid to one unit of effective labor input, then the labor income earned by a worker of type $\theta$, when she works one hour, is $\omega \theta$. A worker's preferences is represented by the utility function, $u_{0}\left(x_{0}\right)+u\left(x_{1}, x_{2}, \cdots, x_{N}\right)-u_{N+1}(\ell)$, where $x_{0}$ is consumption of the public good; $x_{i}, i=1, \cdots, N$ is consumption of the $i^{\text {th }}$ private good; and $\ell$ is labor supply in hours. We impose the following conditions on preferences: (i) $u_{0}(0)=0, u_{0}^{\prime}\left(x_{0}\right)>0$ and $u_{0}^{\prime \prime}\left(x_{0}\right)<0$ for all $x_{0} \geq 0$; and $\lim _{x_{0} \rightarrow 1} u_{0}^{\prime}\left(x_{0}\right)=\infty$. (ii) $u_{N+1}(0)=0$, $u_{N+1}^{\prime}(0)=0, \quad u_{N+1}^{\prime}(\ell)>0$ and $u_{N+1}^{\prime \prime}(\ell)>0$ for all $\ell>0$. Also, $\lim _{\ell \rightarrow 1} u_{N+1}^{\prime}(\ell)=\infty$. (iii) The subutility function $u$ is linear homogeneous and increasing in all its arguments.

As for a capitalist, who does not work and thus does not suffer from the disutility of working, her utility de- 
pends only on her consumption bundle. The preferences of a capitalist are therefore represented by

$$
u_{0}\left(x_{0}\right)+u\left(x_{1}, x_{2}, \cdots, x_{N}\right) .
$$

To finance the production of the public good, the government levies a capital income tax and a labor income tax. Let $\tau_{i}$ be the tax rate on profits made by firms in industry $i$ and $t$ the tax rate on wages. There is no double taxation of physical capital. A tax policy is therefore represented by a list $\left(\left(\tau_{i}\right)_{i=1}^{N}, t\right)$.

We want to explore the impact that taxation has on workers' incentives to migrate, therefore we allow them to be perfectly mobile within the boundaries of the small open economy-at no cost. They could also choose to leave the home country and work in the outside world if they are willing to pay some cost of adjustment. The cost of adjustment of a worker of type $\theta$ denoted by $a(\theta)$, is continuously differentiable, strictly positive, and strictly decreasing in $\theta$.

Let $\bar{\omega}$ denote the wage rate earned by one unit of effective labor abroad. For a worker of type $\theta$, leaving the home country to work in a foreign country will yield a net labor income-net of adjustment costs-equal to $\bar{\omega} \theta \ell-a(\theta)$, if she chooses to work $\ell$ hours.

To influence the tax policy implemented by the government, the owners of the sunk capital stock in each industry get together and form a special-interest group to lobby for favorable tax treatments. This allows them to mitigate the physical capital levy problem. In what follows, the owners of the capital stock in industry $i$ will be referred to as industry lobby $i$. Let $\left(\left(\tau_{i}\right)_{i=1}^{N}, t\right)$ be the tax policy implemented by the government. Under this tax policy, the representative firm in industry $i$, solves the following profit maximization problem:

$$
\max _{L_{i}}\left(1-\tau_{i}\right)\left(\bar{p}_{i} F_{i}\left(K_{i}, L_{i}\right)-\omega L_{i}\right)=\left(1-\tau_{i}\right) \Pi_{i}(\omega) .
$$

In Equation (1), $F_{i}\left(K_{i}, L_{i}\right)$ is the technology used in the production of good $i ; K_{i}$ is the capital stock in this industry; and $L_{i}$ is the labor inputs - measured in effecttive labor units. It is assumed that $F_{i}\left(K_{i}, L_{i}\right)$ is continuously differentiable and strictly increasing in each of its arguments. Furthermore, there are diminishing returns in each factor and the following Inada conditions are satisfied

$$
\lim _{L_{i} \rightarrow 0} \frac{\partial F_{i}}{\partial L_{i}}\left(K_{i}, L_{i}\right)=+\infty \text { and } \lim _{L_{i} \rightarrow+\infty} \frac{\partial F_{i}}{\partial L_{i}}\left(K_{i}, L_{i}\right)=0 \text {. }
$$

As defined, $\Pi_{i}(\omega)$ represents the before-tax profits made by industry $i$, given that it faces the effective labor wage rate $\omega$. Note that the capital income tax does not influence the production plan of the industry. We shall denote by $L_{i}(\omega)$ the demand for effective labor by industry $i$.

As a group, the owners of the capital stock in industry $i$ receive an income equal to $\left(1-\tau_{i}\right) \Pi_{i}(\omega)$, which gives each capitalist in this group a capital income of $\left(\left(1-\tau_{i}\right) \Pi_{i}(\omega)\right) / \gamma_{i}$. Thus, a member of the group that owns capital stock in industry $i$ solves the following utility maximization problem:

$$
\begin{aligned}
& \max _{\left(x_{1}, \cdots, x_{N}\right)}\left(u_{0}\left(x_{0}\right)+u\left(x_{1}, \cdots, x_{N}\right)\right) \\
& =u_{0}\left(x_{0}\right)+v\left(\frac{\left(1-\tau_{i}\right) \Pi_{i}(\omega)}{\gamma_{i}}\right),
\end{aligned}
$$

subject to,

$$
\sum_{i=1}^{N} \bar{p}_{i} x_{i}-\left(\left(1-\tau_{i}\right) \Pi_{i}(\omega)\right) / \gamma_{i}=0 .
$$

Note that in solving, the capitalist takes as given $x_{0}$, the level of the public good provided by the government. Also, in Equation (2), we have let $v(\bullet)$ denote the indirect utility function associated with the consumption of the $N$ private goods, as a function of the after-tax capital income. Since the subutility function associated with the consumption of the private goods is linear homogenous, without any loss of generality we can set $v(1)=1$, which allows us to assert that the utility of a capitalist is the same as her net income.

Consider a worker of type $\theta$, who chooses not to emigrate. Her disposable income is then $(1-t) \omega \theta \ell$, which will be spent on private goods. The utility obtained from the consumption of the private goods is

$$
v((1-t) \omega \theta \ell)=(1-t) \omega \theta \ell
$$

and the disutility from working is $u_{N+1}(\ell)$. Thus she solves the following utility maximization problem:

$$
\begin{aligned}
& \max _{0 \leq \ell \leq 1}\left(u_{0}\left(x_{0}\right)+(1-t) \omega \theta \ell-u_{N+1}(\ell)\right) \\
& =u_{0}\left(x_{0}\right)+\phi(\omega, t, \theta),
\end{aligned}
$$

where we have let $\phi(\omega, t, \theta)$ denote the indirect utility function associated with the consumption of the $N$ private goods and the disutility of working for a worker of type $\theta$, who chooses not to emigrate. Using (ii) of the preference assertions made earlier, we can assert that Equation (3) has a unique interior solution, which is characterized by the first-order condition

$$
(1-t) \omega \theta-u_{N+1}^{\prime}(\ell)=0 \text {. }
$$

The optimal labor supply of a worker of type $\theta$ who chooses not to leave the country is then given by

$$
\ell((1-t) \omega \theta)=\left(u_{N+1}^{\prime}\right)^{-1}((1-t) \omega \theta)
$$

where we have let $\left(u_{N+1}^{\prime}\right)^{-1}$ denote the inverse of $u_{N+1}^{\prime}$. Because the marginal disutility of working is strictly increasing in $\ell$, it is clear that the optimal labor supply of a worker of type $\theta$ who does not emigrate is strictly increasing in $(1-t) \omega \theta$. 
A worker who chooses to leave the country will solve the following utility maximization problem:

$$
\max _{0 \leq \ell \leq 1}\left(\bar{\omega} \theta \ell-a(\theta)-u_{N+1}(\ell)\right)=\bar{\phi}(\theta) .
$$

Note that in the objective function (Equation 4) there is no public good. In essence, we are restricting the individual to a migration decision based on income and adjustment costs. ${ }^{6}$ By doing this we are essentially saying that public goods are not an overriding factor for migration, particularly when the latter has an uncertain, but positive, cost attached.

Now consider a worker with human capital level $\theta$. If she emigrates and decides to work $\ell$ hours, then after paying for the adjustment cost, she is left with a net income of $\bar{\omega} \theta \ell-a(\theta)$. On the other hand, if she decides to stay, then her disposable income is $(1-t) \omega \theta \ell$. It is clear that if

$$
\bar{\omega} \theta-a(\theta) \leq(1-t) \omega \theta
$$

then

$$
\bar{\omega} \theta \ell-a(\theta)<(1-t) \omega \theta \ell
$$

for all $0<\ell<1$, which in turn implies that it is not optimal for her to leave the country. Hence only a worker with a human capital level $\theta$ that satisfies the strict inequality $\bar{\omega} \theta-a(\theta)>(1-t) \omega \theta$ or equivalently, $\bar{\omega}>a(\theta) / \theta+(1-t) \omega$, could entertain the idea of leaving the country. Thus if $\bar{\omega} \leq(1-t) \omega$, then no worker, regardless of her human capital level, will choose to leave the country. The phenomenon of brain drain could only occur if $\bar{\omega}>(1-t) \omega$, i.e., if the net wage rate in the home country is below that abroad. If migration costs are positive then the wage abroad must reflect this, otherwise no emigration will occur. Furthermore, when the utility of the public good is taken into consideration, only a worker with a sufficiently high level of human capital would think of leaving the country.

To see why, note that $a(\theta) / \theta$ is strictly decreasing in $\theta>0$ and tends to infinity when $\theta$ tends to 0 . Hence when $\bar{\omega}>(1-t) \omega$, there exists a unique value of $\theta$, say $\underline{\theta}((1-t) \omega)$, such that

$$
\bar{\omega}=a(\theta) / \theta+(1-t) \omega .
$$

It follows directly from the definition of $\underline{\theta}((1-t) \omega)$ that

$$
\begin{aligned}
& \bar{\omega} \underline{\theta}((1-t) \omega) \ell-a(\underline{\theta}((1-t) \omega)) \\
& <(1-t) \omega \underline{\theta}((1-t) \omega) \ell
\end{aligned}
$$

for all $0<\ell<1$, which in turn implies

$$
\bar{\phi}(\underline{\theta}((1-t) \omega))-\phi(\omega, t, \underline{\theta}((1-t) \omega))<0 .
$$

${ }^{6}$ See Arntz [14] for an empirical study supporting this theoretical assessment for human capital migration.
When the impact of the public good is taken into consideration, the loss in utility suffered by a worker of type $\underline{\theta}((1-t) \omega)$, if she decides to leave the country will be

$$
\bar{\phi}(\underline{\theta}((1-t) \omega))-\phi(\omega, t, \underline{\theta}((1-t) \omega))-u_{0}\left(x_{0}\right),
$$

which is even more pronounced.

To continue, let

$$
q(\theta)=\bar{\phi}(\theta)-\left(u_{0}\left(x_{0}\right)+\phi(\omega, t, \theta)\right)
$$

for all $\theta \geq \underline{\theta}((1-t) \omega)$. Then $q(\underline{\theta}((1-t) \omega))<0$. Through the use of the envelope theorem and the optimal labor supplies (and some manipulation), we get,

$$
\begin{aligned}
& \left(u_{N+1}^{\prime}\right)^{-1}(\bar{\omega} \theta)>\left(u_{N+1}^{\prime}\right)^{-1}(\bar{\omega} \theta-a(\theta)) \\
& \geq\left(u_{N+1}^{\prime}\right)^{-1}((1-t) \omega \theta) .
\end{aligned}
$$

Observe that when $\theta \rightarrow \infty$, we have

$$
\left(u_{N+1}^{\prime}\right)^{-1}((1-t) \omega \theta) \rightarrow 1 .
$$

This last result together with the inequality $\bar{\omega}-(1-t) \omega>0$ implies that $q^{\prime}(\theta)$ is positive and bounded below by $\bar{\omega}-(1-t) \omega$ when $\theta \rightarrow \infty$. Therefore, $q(\theta)$ is strictly increasing to infinity as $\theta$ tends to infinity. Furthermore, $q(\theta)$ is strictly negative at $\underline{\theta}((1-t) \omega)$. Hence there exists a unique value of $\theta$, say $\theta=\bar{\theta}((1-t) \omega)$, such that $q(\bar{\theta}((1-t) \omega))=0$. Therefore, this unique value, $\bar{\theta}$, is the value of $\theta$ that solves $\bar{\phi}(\theta)-\left(u_{0}\left(x_{0}\right)+\phi(\omega, t, \theta)\right)=0$. We refer to this value as the critical human capital level and denote it as $\bar{\theta}\left((1-t) \omega, x_{0}\right)$. The level is strictly increasing in $\omega$ and $x_{0}$, but strictly decreasing in $t$.

\subsection{The Level of the Public Good and the Payoffs Induced by the Tax System}

The aggregate supply of effective labor in the small open economy is

$$
\int_{0}^{\bar{\theta}\left((1-t) \omega, x_{0}\right)} \theta \ell((1-t) \omega \theta) h(\theta) \mathrm{d} \theta,
$$

while the aggregate demand for effective labor by the private sector is $\sum_{j=1}^{N} L_{j}(\omega)$. Furthermore, the total tax revenues collected by the state are given by

$$
\begin{aligned}
& t \omega \int_{0}^{\bar{\theta}\left((1-t) \omega, x_{0}\right)} \theta \ell((1-t) \omega \theta) h(\theta) \mathrm{d} \theta \\
& +\sum_{j=1}^{N} \tau_{j} \Pi_{j}(\omega)
\end{aligned}
$$

These tax revenues are used to pay for the effective labor inputs used in the production of the public good.

The wage rate for effective labor that clears the labor market in the small open economy satisfies the following 
market-clearing condition:

$$
\begin{aligned}
& \int_{0}^{\bar{\theta}\left((1-t) \omega, x_{0}\right)} \theta \ell((1-t) \omega \theta) h(\theta) \mathrm{d} \theta \\
& =\sum_{j=1}^{N} L_{j}(\omega)+t \int_{0}^{\bar{\theta}\left((1-t) \omega, x_{0}\right)} \theta \ell((1-t) \omega \theta) h(\theta) \mathrm{d} \theta \\
& \quad+\frac{1}{\omega} \sum_{j=1}^{N} \tau_{j} \Pi_{j}(\omega) .
\end{aligned}
$$

In order for the labor input to be sufficient for producing the amount of public good $x_{0}$, the following condition must also be satisfied:

$$
\begin{aligned}
& F_{0}\left(K_{0}, t \int_{0}^{\bar{\theta}\left((1-t) \omega, x_{0}\right)} \theta \ell((1-t) \omega \theta) h(\theta) \mathrm{d} \theta+\frac{1}{\omega} \sum_{j=1}^{N} \tau_{j} \Pi_{j}(\omega)\right) \\
& =x_{0} .
\end{aligned}
$$

In Equation (6), $F_{0}\left(K_{0}, L_{0}\right)$ is the production function used in the production of the public good, where $K_{0}$ is the stock of public capital and $L_{0}$ is the input of effective labor. It is assumed that $F_{0}\left(K_{0}, L_{0}\right)$ is continuously differentiable and strictly increasing in each of its variables. Furthermore, the marginal product of labor is strictly decreasing when $L_{0}$ increases and the Inada conditions are satisfied.

Together, Equations (5) and (6) constitute a system of two equations in two unknowns $-\omega$ and $x_{0}$. For any given tax system $\left(\left(\tau_{i}\right)_{i=1}^{N}, t\right)$, we shall let $\omega\left(\left(\tau_{i}\right)_{i=1}^{N}, t\right)$ and $x_{0}\left(\left(\tau_{i}\right)_{i=1}^{N}, t\right)$ be the values of $\omega$ and $x_{0}$ that solve the system. As defined, $\omega\left(\left(\tau_{i}\right)_{i=1}^{N}, t\right)$ is the equilibrium wage paid to one unit of effective labor and $x_{0}\left(\left(\tau_{i}\right)_{i=1}^{N}, t\right)$ the equilibrium amount of public good produced when the tax system $\left(\left(\tau_{i}\right)_{i=1}^{N}, t\right)$ is imposed.

Under the tax policy $\left(\left(\tau_{i}\right)_{i=1}^{N}, t\right)$, the critical level of human capital that separates the workers who stay from those who leave the country is

$$
\bar{\theta}\left((1-t) \omega\left(\left(\tau_{i}\right)_{i=1}^{N}, t\right), x_{0}\left(\left(\tau_{i}\right)_{i=1}^{N}, t\right)\right) .
$$

To keep the notation from becoming too burdensome, we shall write $\theta\left(\left(\tau_{i}\right)_{i=1}^{N}, t\right)$, instead of

$$
\bar{\theta}\left((1-t) \omega\left(\left(\tau_{i}\right)_{i=1}^{N}, t\right), x_{0}\left(\left(\tau_{i}\right)_{i=1}^{N}, t\right)\right),
$$

to denote the critical human capital level. A worker will stay if and only if her type is less than or equal to $\theta\left(\left(\tau_{i}\right)_{i=1}^{N}, t\right)$. For a worker who stays, her utility under the tax policy $\left(\left(\tau_{i}\right)_{i=1}^{N}, t\right)$ is given by

$$
u_{0}\left(x_{0}\left(\left(\tau_{i}\right)_{i=1}^{N}, t\right)\right)+\phi\left(\omega\left(\left(\tau_{i}\right)_{i=1}^{N}, t\right), t, \theta\right) .
$$

As a group, the welfare of the workers who stay is given by

$$
\begin{aligned}
& \int_{0}^{\theta\left(\left(\tau_{i}\right)_{i-1}^{N}, t\right)}\left(u_{0}\left(x_{0}\left(\left(\tau_{i}\right)_{i-1}^{N}, t\right)\right)\right. \\
& \left.+\phi\left(\omega\left(\left(\tau_{i}\right)_{i-1}^{N}, t\right) t, \tilde{\theta}\right)\right) h(\tilde{\theta}) \mathrm{d} \tilde{\theta} \\
& =u_{0}\left(x_{0}\left(\left(\tau_{i}\right)_{i-1}^{N}, t\right)\right) H\left(\theta\left(\left(\tau_{i}\right)_{i-1}^{N}, t\right)+\Phi\left(\left(\tau_{i}\right)_{i-1}^{N}, t\right)\right) .
\end{aligned}
$$

In Equation (7), we have let $H(\theta)$ denote the cumulative distribution of $\theta$. Also note that on the right-hand side of Equation (7) the first part gives the utility from the consumption of the public good, while $\Phi\left(\left(\tau_{i}\right)_{i=1}^{N}, t\right)$ represents the utility from the consumption of the private goods and the disutility of working, for all workers who stay.

As for the owners of the capital stock in industry $j$, $j=1, \cdots, N$, each of them has a capital income equal to

$$
\left(\left(1-\tau_{j}\right) \Pi_{j}\left(\omega\left(\left(\tau_{i}\right)_{i=1}^{N}, t\right)\right)\right) / \gamma_{j},
$$

which according to our earlier calculations is also the capitalist's utility from the consumption of private goods. Her utility under the tax policy $\left(\left(\tau_{i}\right)_{i=1}^{N}, t\right)$ is thus given by,

$$
u_{0}\left(x_{0}\left(\left(\tau_{i}\right)_{i=1}^{N}, t\right)\right)+\frac{1}{\gamma_{j}}\left(1-\tau_{j}\right) \Pi_{j}\left(\omega\left(\left(\tau_{i}\right)_{i=1}^{N}, t\right)\right) .
$$

Therefore, as a group, the owners of the capital stock in industry $j$ obtain the following utility under the tax policy $\left(\left(\tau_{i}\right)_{i=1}^{N}, t\right)$,

$$
\begin{aligned}
& \gamma_{j} u_{0}\left(x_{0}\left(\left(\tau_{i}\right)_{i=1}^{N}, t\right)\right)+\left(1-\tau_{j}\right) \Pi_{j}\left(\omega\left(\left(\tau_{i}\right)_{i=1}^{N}, t\right)\right) \\
& =\gamma_{j} u_{0}\left(x_{0}\left(\left(\tau_{i}\right)_{i=1}^{N}, t\right)\right)+\Psi_{j}\left(\left(\tau_{i}\right)_{i=1}^{N}, t\right) .
\end{aligned}
$$

In Equation (8), we have let $\Psi_{j}\left(\left(\tau_{i}\right)_{i=1}^{N}, t\right)$ denote the utility that this group obtains from the consumption of the private goods under the tax policy $\left(\left(\tau_{i}\right)_{i=1}^{N}, t\right)$.

Without political contributions, the social welfare obtained under the tax policy $\left(\left(\tau_{i}\right)_{i=1}^{N}, t\right)$, is given by

$$
\begin{aligned}
& W\left(\left(\tau_{i}\right)_{i=1}^{N}, t\right) \\
& =u_{0}\left(x_{0}\left(\left(\tau_{i}\right)_{i=1}^{N}, t\right)\right)\left(H\left(\theta\left(\left(\tau_{i}\right)_{i=1}^{N}, t\right)\right)+\gamma_{1}+\cdots+\gamma_{N}\right) \\
& +\Phi\left(\left(\tau_{i}\right)_{i=1}^{N}, t\right)+\sum_{j=1}^{N} \Psi_{j}\left(\left(\tau_{i}\right)_{i=1}^{N}, t\right) .
\end{aligned}
$$

Let $\left(\left(\tau_{i}^{*}\right)_{i=1}^{N}, t^{*}\right)$ be a solution of Equation (9). The equilibrium wage rate and the level of public goods provided under the tax policy $\left(\left(\tau_{i}^{*}\right)_{i=1}^{N}, t^{*}\right)$ are given, respectively, by $\omega\left(\left(\tau_{i}^{*}\right)_{i=1}^{N}, t^{*}\right)$ and $x_{0}\left(\left(\tau_{i}^{*}\right)_{i=1}^{N}, t^{*}\right)$. Now define, 


$$
\begin{aligned}
& \tau^{*}= \\
& \left(\sum_{j=1}^{N} \tau_{j}^{*} \Pi_{j}\left(\omega\left(\left(\tau_{i}^{*}\right)_{i=1}^{N}, t^{*}\right)\right)\right) /\left(\sum_{j=1}^{N} \Pi_{j}\left(\omega\left(\left(\tau_{i}^{*}\right)_{i=1}^{N}, t^{*}\right)\right)\right),
\end{aligned}
$$

then denote by the ordered pair $\left(\tau^{*}, t^{*}\right)$ the tax policy under which capital is taxed uniformly at rate $\tau^{*}$ across industries and wages are taxed at rate $t^{*}$. We claim that $\left(\tau^{*}, t^{*}\right)$ is also a tax policy that maximizes social welfare. Indeed, when the wage rate $\omega\left(\left(\tau_{i}^{*}\right)_{i=1}^{N}, t^{*}\right)$ prevails, the representative firm in industry $j$ will use the same level of effective labor input whether its profits are taxed at rate $\tau_{j}^{*}$ or at rate $\tau^{*}$. As for a worker, if the level of public goods provided remains at $x_{0}\left(\left(\tau_{i}^{*}\right)_{i=1}^{N}, t^{*}\right)$ and if the wage rate $\omega\left(\left(\tau_{i}^{*}\right)_{i=1}^{N}, t^{*}\right)$ still prevails, then her labor supply is still the same when the home government switches from the tax policy $\left(\left(\tau_{i}^{*}\right)_{i=1}^{N}, t^{*}\right)$ to $\left(\tau^{*}, t^{*}\right)$. Given the behavior of the firms and the workers just described, the home government collects the same amount of taxes under the tax policy $\left(\tau^{*}, t^{*}\right)$ as under the tax policy $\left(\left(\tau_{i}^{*}\right)_{i=1}^{N}, t^{*}\right)$, i.e., the same level of public goods is provided when the home government switches from $\left(\left(\tau_{i}^{*}\right)_{i=1}^{N}, t^{*}\right)$ to $\left(\tau^{*}, t^{*}\right)$. We state formally this result in the following lemma:

Lemma 1. In finding the tax policy to generate the revenues needed for the provision of the public goods, the home government can restrict itself to a uniform tax on capital.

In what follows, the ordered pair $(\tau, t)$ represents the tax policy under which capital is uniformly taxed at rate $\tau$ across industries and wages are taxed at rate $t$. When the tax policy $(\tau, t)$ is implemented, the social welfare obtained will be written under the following form:

$$
\begin{aligned}
W(\tau, t)= & u_{o}\left(x_{0}(\tau, t)\right)\left(H(\theta(\tau, t))+\sum_{j=1}^{N} \gamma_{j}\right) \\
& +\Phi(\tau, t)+\sum_{j=1}^{N} \Psi_{j}(\tau, t) .
\end{aligned}
$$

Under this scenario, the home government solves the following social welfare maximization problem:

$$
\max _{(\tau, t)} W(\tau, t) .
$$

While a tax on profits is neutral, a tax on wages distorts the labor-leisure choice of workers and might induce emigration. Therefore, we expect that the home government will favor taxing capital, the immobile, sunk factor, over taxing labor in it efforts to raise the revenues needed in the provision of the public goods. This is sim- ply the traditional capital levy problem, but in general equilibrium context. Proposition 1 confirms this intuittion.

Proposition 1. Let $\tau^{\circ}=\arg \max _{\tau} W(\tau, 0)$ denote the optimal tax rate on capital, given that only this factor of production is taxed to raise the revenues needed for the provision of the public goods. Then, if $\tau^{\circ}<1$, we have $t$ $=0$. On the other hand, if $\tau^{\circ}=1$, then optimal tax policy dictates that all profits be taxed away while wages be taxed at the rate which solves the following maximization problem:

$$
\max _{t} W(1, t)
$$

Furthermore, the optimal tax rate on wages in this case is strictly positive if and only if

$$
\begin{aligned}
& u_{0}^{\prime}\left(F_{0}\left(K_{0}, L_{0}(1,0)\right)\right) \frac{\partial F_{0}}{\partial L_{0}}\left(K_{0}, L_{0}(1,0)\right) \\
& -\omega(1,0)>0 .
\end{aligned}
$$

Proof. See Appendix A.

\section{Lobbying and Human Capital Migration}

When the industry lobbies are active, the global payoff of the home government and the $N$ industry lobbies is given by

$$
\begin{aligned}
& \mathrm{Z}\left(\left(\tau_{i}\right)_{i=1}^{N}, t\right) \\
& =\sum_{j=1}^{N}\left(\gamma_{j} u_{0}\left(x_{0}\left(\left(\tau_{i}\right)_{i=1}^{N}, t\right)\right)+\Psi_{j}\left(\left(\tau_{i}\right)_{i=1}^{N}, t\right)\right) \\
& +\frac{\varepsilon}{1-\varepsilon} W\left(\left(\tau_{i}\right)_{i=1}^{N}, t\right) .
\end{aligned}
$$

The tax policy implemented by the home government is a solution of the following maximization problem:

$$
\max _{\left(\left(_{i}\right)_{i=1}^{N}, t\right)} \mathrm{Z}\left(\left(\tau_{i}\right)_{i=1}^{N}, t\right) .
$$

Let $\left(\left(\hat{\tau}_{i}\right)_{i=1}^{N}, \hat{t}\right)$ be a solution of Equation (15). Under this tax policy, the equilibrium wage rate is $\omega\left(\left(\hat{\tau}_{i}\right)_{i=1}^{N}, \hat{t}\right)$ and the total capital income tax revenues collected are given by

$$
\sum_{j=1}^{N} \tau_{j} \Pi_{j}\left(\omega\left(\left(\hat{\tau}_{i}\right)_{i=1}^{N}, \hat{t}\right)\right)
$$

Let $\left(\hat{\tau}_{i}\right)_{i=1}^{N}$ be a capital income tax policy that satisfies the following condition

$$
\sum_{j=1}^{N} \tau_{j} \Pi_{j}\left(\omega\left(\left(\tau_{i}\right)_{i=1}^{N}, \hat{t}\right)\right)=\sum_{j=1}^{N} \hat{\tau}_{j} \Pi_{j}\left(\omega\left(\left(\hat{\tau}_{i}\right)_{i=1}^{N}, \hat{t}\right)\right) .
$$

It is clear that the tax policy $\left(\left(\tau_{i}\right)_{i=1}^{N}, \hat{t}\right)$ induces the same equilibrium as the tax policy $\left(\left(\hat{\tau}_{i}\right)_{i=1}^{N}, \hat{t}\right)$. That is, 
the equilibrium wage rate and the equilibrium level of public goods provided are the same under both tax policies. Hence the critical human capital levels are also the same under both tax policies, and the utility of a worker who stays under these tax policies remains the same when the home government switches from $\left(\left(\hat{\tau}_{i}\right)_{i=1}^{N}, \hat{t}\right)$ to $\left(\left(\tau_{i}\right)_{i=1}^{N}, \hat{t}\right)$.

Furthermore, because the equilibrium wage rates are the same under both tax policies, the (before-tax) profits earned by each industry are also the same, as are the total capital tax revenues collected. Hence, the welfare of the owners of capital, as a group, does not change when the home government switches from $\left(\left(\hat{\tau}_{i}\right)_{i=1}^{N}, \hat{t}\right)$ to $\left(\left(\tau_{i}\right)_{i=1}^{N}, \hat{t}\right)$, although the welfare of the owners of capital in a particular industry, say $i$, will rise (fall) if $\tau_{i}$ is less than (greater than) $\hat{\tau}_{i}$.

At the global level, the joint payoff of the home government and the $N$ industry lobbies thus does not change when the home government switches from $\left(\left(\hat{\tau}_{i}\right)_{i=1}^{N}, \hat{\hat{t}}\right)$ to $\left(\left(\tau_{i}\right)_{i=1}^{N}, \hat{t}\right)$. In particular, if the home government taxes capital uniformly across industries at the following rate,

$$
\tau=\left(\sum_{j=1}^{N} \hat{\tau}_{j} \Pi_{j}\left(\omega\left(\left(\hat{\tau}_{i}\right)_{i=1}^{N}, \hat{t}\right)\right)\right) /\left(\sum_{j=1}^{N} \Pi_{j}\left(\omega\left(\left(\hat{\tau}_{i}\right)_{i=1}^{N}, \hat{t}\right)\right)\right),
$$

and labor at rate $\hat{t}$, then the joint payoff of the government and the $N$ industries under this tax policy is the same as that under the tax policy $\left(\left(\hat{\tau}_{i}\right)_{i=1}^{N}, \hat{t}\right)$. Therefore, the home government can restrict itself to the case $\tau_{1}=\tau_{2}=\cdots=\tau_{i}=\cdots=\tau_{N}=\tau$, i.e., the case where capital is taxed at the same rate across industries. A tax policy can now be represented by an ordered pair, say $(\tau, t)$, where $\tau$ is the uniform tax rate on capital and $t$ is the tax rate on wages. The gross equilibrium wage rate and the equilibrium level of public goods provided will be denoted, respectively, by $\omega(\tau, t)$ and $x_{0}(\tau, t)$. Given this, we offer up the following proposition.

Proposition 2. Let $\tau^{1}=\arg _{\max _{\tau}} \mathrm{Z}(\tau, 0)$ denote the tax rate on capital imposed by the home government when the $N$ industry lobbies are active, given that it chooses to tax only this factor of production in its efforts to raise the revenues needed for the provision of public goods. Then we have $\tau^{1} \leq \tau^{\circ}$, with strict inequality holding if $\tau^{\circ}<1$.

Proof. See Appendix B.

In other words, if the home government chooses not to tax wages, then the tax rate it imposes on capital is lower when the $N$ industry lobbies are active than when they are inactive: lobbying activities, under this scenario, reduce the capital income tax rate and a fortiori the level of public goods provided.

Here we have simply shown what others have done before us, but in a general equilibrium sense; namely, that the introduction of lobbying can help mitigate the capital levy problem. We have provided additional insight into the argument by explicitly modeling public good provision. Since the government does not use lobbying money towards the production of the public goods, workers see a reduction in their welfare.

Now consider a tax policy $(\tau, t)$, with $\tau>0, t \geq 0$ and $t$ is sufficiently small. Because $t$ is sufficiently small and $\tau>0$, there will be no brain drain when the tax policy $(\tau, t)$ is implemented. For the workers, as a group, their total welfare is given by,

$$
u_{0}\left(x_{0}(\tau, t)\right)\left(1-\sum_{j=1}^{N} \gamma_{j}\right)+\int_{0}^{\infty} \phi(\omega(\tau, t), t, \tilde{\theta}) h(\tilde{\theta}) \mathrm{d} \tilde{\theta} .
$$

As for the owners of capital in the home country, as a group, their total welfare is given by

$$
\sum_{j=1}^{N}\left(\gamma_{j} u_{0}\left(x_{0}(\tau, t)\right)+(1-\tau) \Pi_{j}(\omega(\tau, t))\right) .
$$

Differentiating Equation (16) with respect to $t$, then evaluating the result at $t=0$, we obtain

$$
\begin{aligned}
& u_{0}^{\prime}\left(x_{0}(\tau, 0)\right) \frac{\partial x_{0}}{\partial t}(\tau, 0)\left(1-\sum_{j=1}^{N} \gamma_{j}\right) \\
& +\frac{\partial \omega}{\partial t}(\tau, 0) \int_{0}^{\infty} \tilde{\theta} \ell(\omega(\tau, 0) \tilde{\theta}) h(\tilde{\theta}) \mathrm{d} \tilde{\theta} \\
& -\omega(\tau, 0) \int_{0}^{\infty} \tilde{\theta} \ell(\omega(\tau, 0) \tilde{\theta}) h(\tilde{\theta}) \mathrm{d} \tilde{\theta} .
\end{aligned}
$$

Now we have shown that $(\partial \omega / \partial t)(\tau, 0)>0$. Also, $\left(\partial x_{0} / \partial t\right)(\tau, 0)>0$. Using these results, we can interpret Equation (18) as follows. The first expression represents the rate of change in the welfare of the workers due to a higher level of public goods, which is financed by raising the wage rate slightly above 0 . The second expression represents the rate of change in the wage bill received by the workers due to the rise in the gross equilibrium wage rate $(\partial \omega / \partial t)(\tau, 0)>0$ when the tax rate on wages rises slightly above zero. Both the first and second expressions are positive. The last expression represents the rate of income loss suffered by the workers as $t$ rises in a right neighborhood of 0 . The Inada condition $\lim _{x_{0} \rightarrow 0} u_{0}^{\prime}\left(x_{0}\right)=+\infty$ ensures that the first expression dominates the last expression where $\tau \rightarrow 0$. Therefore, Equation (18) will be positive when $\tau$ is not too high. However, it might be negative if $\tau$ is substantial.

Differentiating Equation (17) with respect to $t$, then evaluating the result at $t=0$, we obtain,

$$
\begin{aligned}
& \sum_{j=1}^{N}\left(\gamma_{j} u_{0}^{\prime}\left(x_{0}(\tau, 0)\right)\right. \\
& \left.\frac{\partial x_{0}}{\partial t}(\tau, 0)-(1-\tau) L_{j}(\omega(\tau, 0)) \frac{\partial \omega}{\partial t}(\tau, 0)\right) .
\end{aligned}
$$


Observe that for each $j=1, \cdots, N$, the expression

$$
\gamma_{j} u_{0}^{\prime}\left(x_{0}(\tau, 0)\right) \frac{\partial x_{0}}{\partial t}(\tau, 0)
$$

represents the rate of change in the welfare of the owners of capital in industry $j$ due to a higher level of public goods provided, while the expression

$$
(1-\tau) L_{j}(\omega(\tau, 0)) \frac{\partial \omega}{\partial t}(\tau, 0)
$$

represents the loss of capital incomes suffered by this group due to a higher wage bill that the industry pays to its workers. As in the case of workers, the first expression dominates the second expression when $\tau$ is small. However, when $\tau$ is substantial, the summation in Equation (19) might be negative. Under such a scenario, raising the tax rate on wages above zero might make the owners of capital in the home economy worse off as a group. Because the impact on the owners of capital of a rise in the wage rate operates indirectly through the rise in the gross equilibrium wage rate and the rise in the level of public goods provided, while the impact on workers operates both directly - through the reductions in labor income - and indirectly - through the rise in the level of public goods provided and the rise in the gross equilibrium wage rate - the impacts, when they are negative, are more adverse to the workers. In particular, it is difficult to imagine that a slight increase in the wage rate above zero will improve the situation of the workers, but make the situation of the owners of capital worse off. Therefore, for any $0<\tau \leq 1$, if the home government has already taxed capital at rate $\tau$ and can raise the welfare of the workers by also taxing wages slightly, then this action also raises the welfare of the owners of capital, which leads to the following,

Proposition 3. The tax rate on wages will be positive, $t>0$, if industry lobbies are active.

Proof. See Appendix C.

Thus, once again in the presence of lobbying firms can alleviate some of their tax burden by providing financial support for a political party's platform. The resulting loss in tax revenues used to fund the provision of the public goods must either be recouped by increasing the taxation on labor income or by reducing the level of public goods. But, any reduction in public goods will lower the welfare of the government's constituents by a larger amount, than a small increase in income taxes. Therefore, taxes on labor income rise in the presence of lobbying and the government concedes the resulting migration by some highly skilled labor in an effort to make the remaining constituents better off, thereby ensuring its persistence in office.

While no dependence of unskilled on skilled labor is built into the model, it is not hard to imagine that if skilled labor leads to job creation for unskilled workers, the reduction at the upper end of the human capital scale will intensify the negative spillover effects. This type of argument would exacerbate the implications of our findings for countries that bleed talent, in particular, or, at least, have an inequitable impact on skill differential between those that leave versus enter from abroad. As such, a restriction on capital lobbying would likely imply a more efficient solution.

\section{Concluding Remarks}

By modeling the two-sided expropriations problem, we have shown how changes in tax policy can influence migration patterns of skilled workers. By doing so, we have explored some indirect implications of the traditional problem which has yet to be examined. For example, whether or not a country is human capital intensive will depend directly on the taxation of skilled labor and its mobility and indirectly on policies guiding political contributions and capital income taxes. The more lax the policies are on the indirect effects, the greater the direct incentives for migration of highly skilled individuals will be.

Modeling the expropriation decision in a general equilibrium framework also affords a commentary on the externality caused by physical capital lobbying on human capital migration. For example, all else being equal, if adjustment costs rise in the home country, then a greater number of highly skilled workers remain and the economy is now more human capital intensive; this, according to endogenous growth theory, leads to an improved economic outlook. Of course, this goes for countries that bleed talent. For countries that rely on attracting skilled labor from abroad, the results are the opposite. If migration costs rise, then fewer workers are choosing to emigrate. Therefore, countries that relied on skilled labor to supplement their workforce may fall short of their necessary requirements.

Finally, we show that while equilibrium under social welfare maximization calls for a high capital income tax. This result falls apart with the allowance of lobbying. Fortunately, the mobility of skilled labor provides a deterrent to the government when determining the structure of taxation. Hence, labor income taxation remains low even in the face of lobbying. This result casts doubt on previous findings that believe restrictions on lobbying have ambiguous results (e.g. Marceau and Smart [7]). Certainly, in our framework such restrictions appear to be positive in terms of providing increased welfare for government constituents. To be fair, unlike Marceau and Smart [7], we include a labor-migration choice for a worker, which acts as a constraint.

\section{REFERENCES}

[1] J. B. Davies and J. Whalley, "Taxes and Capital Forma- 
tion: How Important Is Human Capital?” In: D. Bernheim and J. Shoven (Eds.), National Saving and Economic Performance, University of Chicago Press, Chicago, 1991, pp. 169-197.

[2] J. Gibson and D. McKenzie, "Eight Questions about Brain Drain,” Journal of Economic Perspectives, Vol. 25, No. 3, 2011, pp. 107-128. http://dx.doi.org/10.1257/jep.25.3.107

[3] F. Docquier and H. Rapoport, "Globalization, Brain Drain, and Development," Journal of Economic Literature, Vol. 50, No. 3, 2012, pp. 681-730. http://dx.doi.org/10.1257/jel.50.3.681

[4] J. J. Heckman and P. J. Klenow, "Human Capital Policy," In: M. Boskin, Ed., Capital Formation, Hoover Institution Press, 1998.

[5] J. J. Heckman, L. Lochner and C. Taber, “General Equilibrium Cost-Benefit Analysis of Education and Tax Policies,” In: G. Ranis and L. K. Raut, Eds., Trade, Growth and Development: Essays in honor of Prof. T.N. Srinivasan, Contributions to Economic Analysis, Vol. 242, Elsevier Science, Amsterdam, 1999, pp. 291-349.

[6] B. Eichengreen, "The Capital Levy in the Theory and Practice,” In: R. Dornbusch and M. Draghi, Eds., Public Debt Management: Theory and History, Cambridge University Press, London, 1990, pp. 191-220. http://dx.doi.org/10.1017/CBO9780511628528.014

[7] N. Marceau and M. Smart, "Corporate Lobbying and Commitment Failure in Capital Taxation,” American Economic Review, Vol. 93, No. 1, 2003, pp. 241-251. http://dx.doi.org/10.1257/000282803321455241

[8] S. Coate and S. Morris, "Policy Persistence," American Economic Review, Vol. 89, No. 5, 1999, pp. 1327-1336. http://dx.doi.org/10.1257/aer.89.5.1327

[9] M. R. Garfinkel and J. Lee, "Political Influence and the Dynamic Consistency of Policy," American Economic Review, Vol. 90, No. 3, 2000, pp. 649-666. http://dx.doi.org/10.1257/aer.90.3.649

[10] B. D. Bernheim and M. D. Whinston, "Menu Auctions, Resource Allocation, and Economic Influence,” Quarterly Journal of Economics, Vol. 101, No. 1, 1986, pp. 1-31. http://dx.doi.org/10.2307/1884639

[11] K. Kollman, J. H. Miller and S. E. Page, "Computational Models in Political Economy,” MIT Press, Massachusetts, 2003.

[12] P. Pecorino, "Tax Structure and Growth in a Model with Human Capital,” Journal of Public Economics, Vol. 52, No. 2, 1993, pp. 251-271.

http://dx.doi.org/10.1016/0047-2727(93)90023-M

[13] A. Razin, E. Sadka and P. Swagel, "Tax Burden and Migration: A Political Economy Theory and Evidence," Journal of Public Economics, Vol. 85, No. 2, 2002, pp. 167-190. http://dx.doi.org/10.1016/S0047-2727(01)00091-3

[14] M. Arntz, "What Attracts Human Capital? Understanding the Skill Composition of Interregional Job Matches in Germany," Regional Studies, Vol. 44, No. 4, 2010, pp. 423-441. http://dx.doi.org/10.1080/00343400802663532 


\section{Appendix A}

In proving Proposition 1 , we let $\left((\tau)^{*}, t^{*}\right)$ be a tax policy that maximizes social welfare. We have

$$
\begin{aligned}
& W\left((\tau)^{*}, t^{*}\right) \leq u_{0}\left(F_{0}\left(K_{0}, L_{0}\left((\tau)^{*}, t^{*}\right)\right)\right) \\
& +\sum_{j=1}^{N} \bar{p}_{j}\left(F_{0}\left(K_{0}, L_{0}\left((\tau)^{*}, t^{*}\right)\right)\right) \\
& -\theta\left((\tau)^{*}, t^{*}\right) \\
& -\int_{0} u_{N+1}\left(\ell\left(\left(1-t^{*}\right)\right) \omega\left((\tau)^{*}, t^{*}\right) \tilde{\theta}\right) h(\tilde{\theta}) \mathrm{d} \tilde{\theta} .
\end{aligned}
$$

where we have denoted by

$$
\begin{aligned}
L_{0}(\tau, t)= & \frac{\tau}{\omega(\tau, t)} \sum_{j=1}^{N} \Pi_{j}(\omega(\tau, t)) \\
& +t \int_{0}^{\theta(\tau, t)} \tilde{\theta} \ell((1-t) \omega(\tau, t) \tilde{\theta}) h(\tilde{\theta}) \mathrm{d} \tilde{\theta}
\end{aligned}
$$

the equilibrium level of effective labor input in the public sector under the tax policy $(\tau, t)$. Next, let $\bar{\omega}$ be the value of $\omega$ that solves the following equation

$$
\begin{aligned}
& \int_{0}^{\infty} \tilde{\theta} \ell(\omega \tilde{\theta}) h(\tilde{\theta}) \mathrm{d} \tilde{\theta} \\
& =\int_{0}^{\theta\left((\tau)^{*}, t^{*}\right)} \tilde{\theta}\left(\ell\left(\left(1-t^{*}\right) \omega\left((\tau)^{*}, t^{*}\right) \tilde{\theta}\right) h(\tilde{\theta}) \mathrm{d} \tilde{\theta}\right.
\end{aligned}
$$

As defined, $\bar{\omega}$ is the wage rate that must prevail to elicit the same aggregate supply of effective labor as the tax policy $\left((\tau)^{*}, t^{*}\right)$, given that wages are not taxed and that emigration is forbidden. We claim that

$$
\begin{aligned}
& \int_{0}^{\infty} u_{N+1}(\ell(\bar{\omega} \tilde{\theta})) h(\tilde{\theta}) \mathrm{d} \tilde{\theta} \\
& \leq \int_{0}^{\theta\left((\tau)^{*}, t^{*}\right)} u_{N+1}\left(\ell\left(\left(1-t^{*}\right)\right) \omega\left((\tau)^{*}, t^{*}\right) \tilde{\theta}\right) h(\tilde{\theta}) \mathrm{d} \tilde{\theta}
\end{aligned}
$$

To establish the claim, let $\omega(\theta), \theta \geq \theta\left(\tau^{*}, t^{*}\right)$, be the wage rate that satisfies the following condition:

$$
\begin{aligned}
& \int_{0}^{\theta} \theta \ell(\omega(\theta) \tilde{\theta}) h(\tilde{\theta}) \mathrm{d} \tilde{\theta} \\
& \leq \int_{0}^{\theta\left((\tau)^{*}, t^{*}\right)} \tilde{\theta}\left(\ell\left(\left(1-t^{*}\right)\right) \omega\left((\tau)^{*}, t^{*}\right) \tilde{\theta}\right) h(\tilde{\theta}) \mathrm{d} \tilde{\theta}
\end{aligned}
$$

and for all $\theta \geq \theta\left(\tau^{*}, t^{*}\right)$, let

$$
\beta(\theta)=\int_{0}^{\theta} u_{N+1}(\ell(\omega(\theta) \tilde{\theta})) h(\tilde{\theta}) \mathrm{d} \tilde{\theta}
$$

Differentiating the expression on the left-hand side of
Equation (4a), with respect to $\theta$, we obtain

$$
\begin{aligned}
& \theta \ell(\omega(\theta) \theta) h(\theta) \\
& +\int_{0}^{\theta} \tilde{\theta}^{2} \ell^{\prime}(\omega(\theta) \tilde{\theta}) \omega^{\prime}(\theta) h(\tilde{\theta}) \mathrm{d} \tilde{\theta}=0
\end{aligned}
$$

Differentiating Equation (5a) with respect to $\theta$, we find that $\beta^{\prime}(\theta) \leq 0$, where the right-hand side is obtained from Equation (6a). Hence, $\beta(\theta), \theta \geq \theta\left(\tau^{*}, t^{*}\right)$, is non-increasing. Furthermore, when $\theta=\theta\left(\tau^{*}, t^{*}\right)$, we have

$$
\omega\left(\theta\left(\tau^{*}, t^{*}\right)\right)=\left(1-t^{*}\right) \omega\left(\tau^{*}, t^{*}\right),
$$

which implies

$$
\begin{aligned}
& \beta\left(\theta\left(\tau^{*}, t^{*}\right)\right) \\
& =\int_{0}^{\theta\left(\tau^{*} t^{*}\right)} u_{N+1}\left(\ell\left(\left(1-t^{*}\right) \omega\left(\tau^{*}, t^{*}\right) \tilde{\theta}\right)\right) h(\tilde{\theta}) \mathrm{d} \tilde{\theta} .
\end{aligned}
$$

Hence the claim is proved. Note that when $\tau^{\circ}<1$, we have

$$
\begin{aligned}
& u_{0}^{\prime}\left(F_{0}\left(K_{0}, L_{0}\left(\tau^{\circ}, 0\right)\right)\right) \frac{\partial F_{0}}{\partial L_{0}}\left(K_{0}, L_{0}\left(\tau^{\circ}, 0\right)\right) \\
& -\omega\left(\tau^{\circ}, 0\right)=0 .
\end{aligned}
$$

Furthermore, according to profit maximization,

$$
\bar{p}_{j} \frac{\partial F_{j}}{\partial L_{j}}\left(K_{j}, L_{j}\left(\omega\left(\tau^{\circ}, 0\right)\right)\right)-\omega\left(\tau^{\circ}, 0\right)=0,
$$

for $j=1, \cdots, N$. Also,

$$
\begin{aligned}
& L_{0}\left(\tau^{\circ}, 0\right)+\sum_{j=1}^{N} L_{j}\left(\omega\left(\tau^{\circ}, 0\right)\right) \\
& =\int_{0}^{\infty} \tilde{\theta} \ell\left(\omega\left(\tau^{\circ}, 0\right) \tilde{\theta}\right) h(\tilde{\theta}) \mathrm{d} \tilde{\theta}
\end{aligned}
$$

is the form assumed by the market-clearing condition for labor under the tax policy $\left(\tau^{\circ}, 0\right)$. Hence

$$
L_{0}\left(\tau^{\circ}, 0\right), L_{1}\left(\tau^{\circ}, 0\right), \cdots, L_{N}\left(\tau^{\circ}, 0\right),
$$

and $\lambda=\omega\left(\tau^{\circ}, 0\right)$ constitute the solution of the maximization problem for the case where $\omega=\omega\left(\tau^{\circ}, 0\right)$. If we let $\omega^{1}$ be the wage rate at which $\lambda(\omega)$ crosses the forty-five degree line, then because

$$
\lambda\left(\omega\left(\tau^{\circ}, 0\right)\right)=\omega\left(\tau^{\circ}, 0\right)
$$

we must have $\omega\left(\tau^{\circ}, 0\right)=\omega^{1}$. We have just shown that when $\tau^{\circ}<1$, the socially optimal tax to policy dictates that wages should not be taxed, but capital should be taxed at rate $\tau^{\circ}$. 
Next, consider the scenario $\tau^{\circ}=1$. This scenario occurs when

$$
\begin{aligned}
& u_{0}^{\prime}\left(F_{0}\left(K_{0}, L_{0}(1,0)\right)\right) \frac{\partial F_{0}}{\partial L_{0}}\left(K_{0}, L_{0}(1,0)\right) \\
& -\omega(1,0) \geq 0 .
\end{aligned}
$$

If inequality holds in Equation (10a), then the argument just presented for the case $\tau^{\circ}<1$ can be repeated verbatim obtain the same conclusion: capital should be taxed at rate $\tau^{\circ}=1$, but wages should not be taxed.

We now claim that if Equation (10a) is a strict inequality, then the optimal tax rate on wages is positive. Indeed, if it is not optimal to tax wages, then capital will be taxed at rate $\tau^{\circ}$ and the optimal social welfare will be given by $W\left(\tau^{\circ}, 0\right)=W(1,0)$. However, when $(10 \mathrm{a})$ is a strict inequality, we must have $(\partial W / \partial t)(1,0)>0$, i.e., social welfare can be raised by also taxing wages after having taxed away all profits.

\section{Appendix B}

If $\tau^{\circ}=1$, then obviously $\tau^{\circ} \geq \tau^{1}$, as claimed by the proposition. We now show that if $\tau^{\circ}<1$, then $\tau^{\circ}>\tau^{1}$. To this end, suppose that the home government chooses to tax only capital and at rate $\tau>0$. We have $\omega(\tau, 0)>\bar{\omega}$ and that both the equilibrium wage rate $\omega(\tau, 0)$ and the equilibrium level of the public good $x_{0}(\tau, 0)$ provided rise with $\tau$. That is, as $\tau$ rises the tax policy induces no brain drain and raises the welfare of the workers as a group. The social welfare obtained under this tax policy is given by

$$
\begin{aligned}
& W(\tau, 0)=\sum_{j=1}^{N}\left[\gamma_{j} u_{0}\left(x_{0}(\tau, 0)\right)+\Psi(\tau, 0)\right] \\
& +\left(u_{0}\left(x_{0}(\tau, 0)\right)\right) u_{0}\left(x_{0}(\tau, 0)\right)\left[1-\sum_{j=1}^{N} \gamma_{j}\right]+\Phi(\tau, 0) .
\end{aligned}
$$

Differentiating Equation (11a) with respect to $\tau$, we obtain

$$
\begin{aligned}
& \frac{\partial W(\tau, 0)}{\partial t}=\frac{\partial}{\partial \tau}\left(\sum_{j=1}^{N}\left[\gamma_{j} u_{0}\left(x_{0}(\tau, 0)\right)+\Psi(\tau, 0)\right]\right) \\
& +\frac{\partial}{\partial \tau}\left(\left(u_{0}\left(x_{0}(\tau, 0)\right)\right) u_{0}\left(x_{0}(\tau, 0)\right)\left[1+\sum_{j=1}^{N} \gamma_{j}\right]\right. \\
& +\Phi(\tau, 0)) .
\end{aligned}
$$

Note that if $\tau^{\circ}<1$, then $\partial W(\tau, 0) / \partial \tau<0$ for all $\tau^{\circ} \leq \tau \leq 1$. Using this result and the fact that

$$
\frac{\partial}{\partial \tau}\left(\left(u_{0}\left(x_{0}(\tau, 0)\right)\right) u_{0}\left(x_{0}(\tau, 0)\right)\left[1-\sum_{j=1}^{N} \gamma_{j}\right]+\Phi(\tau, 0)\right)>0
$$

we can assert that if $\tau \geq \tau^{\circ}$, then

$$
\frac{\partial}{\partial \tau}\left(\sum_{j=1}^{N}\left[\gamma_{j} u_{0}\left(x_{0}(\tau, 0)\right)+\Psi(\tau, 0)\right]\right)<0 .
$$

Now the joint payoff for the home government and the $N$ industry lobbies under the tax policy $(\tau, 0)$ is given by

$$
\begin{aligned}
\Gamma(\tau, 0) & =\sum_{j=1}^{N}\left[\gamma_{j} u_{0}\left(x_{0}(\tau, 0)\right)+\Psi(\tau, 0)\right] \\
& +\frac{\varepsilon}{1-\varepsilon} W(\tau, 0) .
\end{aligned}
$$

For any $\tau \geq \tau^{\circ}$, we have

$$
\begin{aligned}
\frac{\partial \Gamma(\tau, 0)}{\partial \tau}= & \frac{\partial}{\partial \tau}\left(\sum_{j=1}^{N}\left[\gamma_{j} u_{0}\left(x_{0}(\tau, 0)\right)+\Psi(\tau, 0)\right]\right) \\
& +\frac{\varepsilon}{1-\varepsilon} \frac{\partial W(\tau, 0)}{\partial \tau}<0,
\end{aligned}
$$

which has been obtained with the help of Equation (12a) and the fact that $\partial W(\tau, 0) / \partial \tau<0$ when $\tau^{\circ} \leq \tau \leq 1$. We have just shown that the joint payoff for the home government, given that only capital is taxed, is strictly decreasing in the interval $\tau^{\circ} \leq \tau \leq 1$. Hence, when $\tau^{\circ}<1$, the value of $\tau$, namely $\tau^{1}$, that solves the maximization problem in Proposition 2 must be strictly less than $\tau^{\circ}$. Proposition 2 is now proved.

\section{Appendix C}

There are two cases to consider in the proof of Proposition 3: $\tau^{\circ}<1$ and $\tau^{\circ}=1$. When $\tau^{\circ}<1$, we have $\tau^{1}<\tau^{\circ}$ according to Proposition 2. Because $\tau^{1}<\tau^{\circ}$, we must have

$$
\begin{aligned}
& u_{0}^{\prime}\left(F_{0}\left(K_{0}, L_{0}\left(\tau^{1}, 0\right)\right)\right) \frac{\partial F_{0}}{\partial L_{0}}\left(K_{0}, L_{0}\left(\tau^{1}, 0\right)\right) \\
& -\omega\left(\tau^{1}, 0\right)>0 .
\end{aligned}
$$

Note that Equation (15a) also implies that

$$
(\partial W / \partial t)\left(\tau^{1}, 0\right)>0 \text {. }
$$

Therefore, we claim that

$$
\begin{aligned}
& \sum_{j=1}^{N}\left[\gamma_{j} u_{0}^{\prime}\left(x_{0}\left(\tau^{1}, 0\right)\right) \frac{\partial x_{0}}{\partial t}\left(\tau^{1}, 0\right)\right. \\
& \left.-\left(1-\tau^{1}\right) L_{j}\left(\omega\left(\tau^{1}, 0\right)\right) \frac{\partial \omega}{\partial t}\left(\tau^{1}, 0\right)\right]>0 .
\end{aligned}
$$

Indeed, if this is not the case, then we must have 


$$
\begin{aligned}
& {\left[u_{0}^{\prime}\left(x_{0}\left(\tau^{1}, 0\right)\right)\right]\left[1-\sum_{j=1}^{N} \gamma_{j}\right]} \\
& +\frac{\partial \omega}{\partial t}\left(\tau^{1}, 0\right) \int_{0}^{\infty} \tilde{\theta} \ell\left(\omega\left(\tau^{1}, 0\right) \tilde{\theta}\right) h(\tilde{\theta}) \mathrm{d} \tilde{\theta} \\
& -\omega\left(\tau^{1}, 0\right) \int_{0}^{\infty} \tilde{\theta} \ell\left(\omega\left(\tau^{1}, 0\right) \tilde{\theta}\right) h(\tilde{\theta}) \mathrm{d} \tilde{\theta}<0 .
\end{aligned}
$$

Because the sum of the expression on the left-hand side of Equation (16a) and the expression in Equation (17a) is equal to $(\partial W / \partial t)\left(\tau^{1}, 0\right)$, we will be led to the conclusion that $(\partial W / \partial t)\left(\tau^{1}, 0\right)<0$ if Equation (16a) does not hold, a conclusion that is opposite to the result $(\partial W / \partial t)\left(\tau^{1}, 0\right)>0$, already established. Using Equation (16a) and the result $(\partial W / \partial t)\left(\tau^{1}, 0\right)>0$, we obtain

$$
\begin{aligned}
\frac{\partial \Gamma}{\partial t}\left(\tau^{1}, 0\right)= & \sum_{j=1}^{N}\left[\gamma_{j} u_{0}^{\prime}\left(x_{0}\left(\tau^{1}, 0\right)\right) \frac{\partial x_{0}}{\partial t}\left(\tau^{1}, 0\right)\right. \\
& \left.-\left(1-\tau^{1}\right) L_{j}\left(\omega\left(\tau^{1}, 0\right) \frac{\partial \omega}{\partial t}\left(\tau^{1}, 0\right)\right)\right] \\
& +\frac{\varepsilon}{1-\varepsilon} \frac{\partial W}{\partial t}\left(\tau^{1}, 0\right)>0
\end{aligned}
$$

It follows directly from Equation (18a) that $\Gamma\left(\tau^{1}, t\right)>\Gamma\left(\tau^{1}, 0\right)$, i.e., taxing capital at rate $\tau^{1}$ and wages at a low rate $t>0$ will yield a higher joint payoff for the home government and the $N$ industry lobbies than taxing only capital. Thus when the industry lobbies are active, their lobbying activities will induce the home government to tax wages at a positive rate.

Having considered the case $\tau^{\circ}<1$, we next consider the case $\tau^{\circ}=1$. The case $\tau^{\circ}=1$ arises when Equation (14a), of Appendix B, holds. If Equation (14a) holds with equality, then $\tau^{1}<\tau^{\circ}$ and the preceding argument can be repeated verbatim to show that the tax rate on wages is positive. If Equation (14a) holds with strict inequality, then $(\partial W / \partial t)(1,0)>0$. The preceding argument can be repeated verbatim with $\tau^{1}$ replaced by 1 to show that $(\partial \Gamma / \partial t)(1,0)>0$, i.e.

$$
(\partial \Gamma / \partial t)(1, t)>(\partial \Gamma / \partial t)(1,0)
$$

for small values of $t$. The tax rate on wages is thus also positive in this case. The proof of Proposition 3 is now complete. 